\title{
Time Competition. The New Strategic Frontier
}

\author{
Chiara Demartini, Piero Mella
}

Department of Business Research, University of Pavia, Pavia, Italy.

Email: cdemartini@eco.unipv.it, piero.mella@unipv.it

Receive January $17^{\text {th }}, 2011$; revised March $16^{\text {th }}, 2011$; accepted April $26^{\text {th }}, 2011$.

\begin{abstract}
The acceleration of change necessitates strategies to control time, considered not only as a variable that influences the temporal evolution of phenomena but as one that directly influences phenomena itself. This study tries to present the logic of time compression and time to market, as well as the main instruments for the formulation of time-based strategies, not only by observing how the value of time is perceived as a contraction of production and distribution lead times but also by considering the choice of the most opportune moment to start a business and introduce (or withdraw) a new product. Starting from a discussion of time-based competition managerial approaches, this study develops a theoretical framework showing different time-based methodologies (JIT, MRP, OPT, FMS, PERT, HSM) that help management to adopt time-based strategies. It also puts forward a taxonomy of time-based strategies as well as a logical strategic path to time value.
\end{abstract}

Keywords: Time Compression, Time-Based Strategy, Time Value, Strategic Competition

\section{Introduction: Competing Against Time}

In the present competitive context of increasing change and growing globalization [1-3], the focus on mass production, structural efficiency, the control of worker productivity has been replaced by the strategic importance of time compression, both regarding the shortening of production and distribution times and the reduction of time-to-market in the introduction of new products [4].

This paper will present the logic and basic instruments for a time-based strategy [5,6] based on time compression $[7,8]$ and the shortening of time-to-market.

For firms that produce and are affected by such phenomena, time has become as much a critical factor for those companies affected by it as a factor of competitive advantage for those that can control it [9].

Time has been defined as "an essential aspect of strategy" [10]. Time becomes not only a factor but also a fundamental strategic actor, and firms have the not so easy and ambitious task of "competing against time" [11].

If Planning is learning [12] then large companies that have become aware of the value of time are equally aware that the competition against time requires a learning and control process involving the entire organizational structure.

However, to achieve time-based competition a cultural change is required that must spread throughout the entire organization, enhancing coordinated actions at all the strategic levels.

We can identify several guiding principles for time -based competition (Figure 1).

Previous argumentations affect manufacturing as well as service firms, since McLaughlin and Fitzsimmons found time-compression to be a successful strategy in both defensive and offensive strategic approach within service firms [14].

These guiding principles of time-based competition are merely the logical extension of the Just-in-Time principle to all aspects of the value production cycle $[15,16]$. The next section will critically review the time management techniques as well as the two facets of time compression: at the production and logistical system level and the business system level of the firm.

\section{Time Compression Techniques}

Time compression represents a factor that reduces costs and improves quality, since it reduces setup times and downtimes, stabilizes production flows, and involves human resources in the increase in productivity $[17,18]$ and customers value it by their willing to pay higher prices [19].

Several methods, generally recognized as being effective, can be used to achieve time compression in production: 
GUIDING PRINCIPLES FOR TIME-BASED COMPETITION

\begin{tabular}{|c|c|}
\hline $\begin{array}{l}\text { A) PHILOSOPHY OF VALUE ADDED PRODUC- } \\
\text { TION }\end{array}$ & $\begin{array}{l}\Rightarrow \quad \text { continually improve any function that produces value added by impacting produc- } \\
\text { tion and the delivery of the product to the customer or the rendering of the service }\end{array}$ \\
\hline $\begin{array}{l}\text { B) REDUCTION IN THE COMPLEXITY OF THE } \\
\text { ORGANIZATIONAL SYSTEM }\end{array}$ & $\begin{array}{l}\Rightarrow \text { seek simplicity by reducing codes, standardizing parts, modularizing, and simplify- } \\
\text { ing production processes }\end{array}$ \\
\hline C) GLOBAL VISION OF THE PROCESS & $\begin{array}{l}\Rightarrow \text { make the process more streamlined and fluid by eliminating "waste"; that is, those } \\
\text { activities that do not add value to the product }\end{array}$ \\
\hline $\begin{array}{l}\text { D) INCREMENTAL IMPROVEMENT IN PROD- } \\
\text { UCTS }\end{array}$ & anticipating and incrementally achieving product improvements \\
\hline $\begin{array}{l}\text { E) INTERCONNECTED INFORMATION SYS- } \\
\text { TEMS }\end{array}$ & $\begin{array}{l}\Rightarrow \text { design and set up information systems that guarantee the immediate circulation and } \\
\text { use of information }\end{array}$ \\
\hline F) PARTNERSHIPS WITH SUPPLIERS & undertake long-term relationships with suppliers based on trust and reliability \\
\hline G) DECENTRALIZE DECISION-MAKING & decentralize decision-making to eliminate wasting time for authorization requests \\
\hline $\begin{array}{l}\text { H) SHARING OF VALUES AND LEARNING } \\
\text { ORGANIZATION }\end{array}$ & \\
\hline
\end{tabular}

Figure 1. Guiding principles for time-based competition. Adapted from [13: pp. 260-261].

1) for firms that produce production lots, Just-in-Time (JIT) $[20,21]$;

2) for firms that operate with a continual process, the MRP and OPT methods [22-25] are appropriate in addition to JIT [26];

3) for construction firms and those that carry out large projects, reticular programming (PERT), in all its variants, is appropriate [27,28];

4) for the development of new products, the High Speed Management [29,30] rules are valid, the specific aspects of which represent the adaptation of the JustIn-Time concepts for time compression in the management of the product portfolio.

\subsection{JIT and Toyotism}

Originating with Toyota, JIT soon spread along with the total quality philosophy, lending its name to a new production policy: Toyotism-a synonym for flexibility and stock reductions.

The principles of Toyotism are very simple [21,31]:

1) Jidoka, translated with the neologism autonomation: the maximum automation of facilities is required, along with autonomous functioning that is, above all, capable of the on-line testing of the functional quality; this means the automatic control of defects throughout the entire production process;

2) Shojinka, that is, flexibility in the use of manpower:

a) the worker must know how to do many simple tasks in order to be employed flexibly;

b) the amount of labor should vary with the variation in production levels; the workloads must be balanced; idleness must be eliminated;

3) Soikufu, that is, inventiveness and creativity: the experience and creativity of each worker must be exploited by involving them in the improvement of productivity and quality;

4) JIT: this is a basic principle that gives its name to the entire philosophy: try to reduce lead times to zero at all moments of the production process;

5) Customer satisfaction: the quality of production is central to customer satisfaction and should be improved by adding to the traditional product a series of complementary services [32].

Just-in-Time is not only a principle but a consolidated structure of engineering techniques designed to continually improve the use of the available resources by seeking flexibility and elasticity in production in order to guarantee timeliness in every phase of organizational processes [33].

\subsection{Time Compression in Non-JIT-Oriented Companies}

Production planning, that is, the sequence and timing of production activities, cannot ignore time as a variable to manage in order to favor the synchronization of production lines, flexibility (production mix), and the elasticity (in volumes) of the production processes [34].

Independently of the Just-in-Time approach, these aims can also be pursued through material handling activities.

The careful management of production supplies and stocks is perhaps the simplest time compression measure, 
and supply lead times can be kept under control so as to make available only the necessary materials.

There are a number of techniques to implement these forms of time compression. In the sections below we shall consider the principles of

- Material Requirements Planning,

- Optimized Production Technology,

- Flexible Manufacturing System,

- PERT method.

\subsection{Time Compression and the MRP System}

Material Requirements Planning (MRP) carries out material planning by material requirements calculationsto determine the quantity and types of materials needed - and time scheduling, to synchronize supplies with the rhythms of the production processes [24,35].

Material requirements calculations is carried out starting from the planning principle of production (which specifies the plan for the volume of final goods to produce) by applying the unit needs data contained in the bill of material for each level of the product structure.

Gross requirements, i.e. the quantities necessary for each code, as well as net requirements, possibly supplemented by the safety stock, are determined in order to specify the supply plan (plan for orders) that indicates the date when the production or purchase order must be issued; in this way the codes will be produced or purchased only when there is actually a demand for them.

Time scheduling plans the availability of materials so that the supplies result in the components reaching the warehouse with a minimum of time before they are removed; producing cost savings effects.

MRP techniques can operate according to two different approaches: the regenerative systems and incremental systems approaches [36].

The regenerative systems method periodically calculates the full explosion of needs based on the most recent production program.

Incremental systems, or net change system, provide for actions on limited portions of the partial explosion; only the requirements for the codes involved in the variation are recalculated.

Such systems are efficient in the case of data gathering close together in time, since they reduce waiting times, even though at times they require regenerative interventions. In this sense the two approaches are often used together, with the first adopted for periodic realignments and the second for small intra-period variations.

The benefits from the use of MRP techniques also relates to the optimization of inventory space and a reduction in delivery times [37].

An evolution of MRP is represented by Manufacturing Resources Planning, MRPII, which extends the planning process to all the production resources: productive capacity, investment and personnel [38].

Recently MRPII was also extended to obtain indications on maintenance management, quality control and industrial accounting: this represents the content of MRPIII.

\subsection{Time Compression and the OPT System}

MRP and JIT are based on the assumption there are no limits to productive.

Optimized Production Technology (OPT) [25,39,40] abandons this assumption and states the twofold objective of:

1) Planning the optimal sequence of operations, taking into account both existing productive capacity and the priorities of the different operations;

2) Identifying the optimal use of critical resources and facilities, as well as minimizing work in process.

In this way the optimization of workloads, inventory reduction, the shortening of work times, and the reduction in relative costs thus become a consequence and not an objective, as in MRP and JIT.

The procedure considers, sequentially and at fixed time intervals, how available productive factors should be utilized in order to meet demand, after having established the priorities for each operation by using weighted functions containing a certain number of variables such as: the assortment of desired products, deadlines, the safety stock and the use of resources that present bottleneck risks.

By using the list of products, sorted by priority, to obtain the plan accordingly allocates resources in order to favour the production of higher priority products, considering the availability of productive inputs.

OPT planning devises a master plan that delivers the global optimization of production through local optimizations determined by a series of interconnected partial plans, each of which searches for the optimum partial plan in a specific area of production.

\subsection{Time Compression FMSs}

Flexible Manufacturing Systems (FMSs) [41-44] represent the extreme development of non-JIT techniques for time compression in production, since the automatic change in machinery and tools, machine manufacturing, and data processing for manufacturing processes lead to completely automated production and inventory lines through the integration of planning and the control of operating machinery into an integrated computerized control system that minimizes the transit times of materials and products within the system.

To overcome production bottlenecks a plan is used that thoroughly exploits reticular and dynamic planning 
techniques.

The extreme evolution of the FMSs is represented by the automated factory where all the physical flows and all the manufacturing are planned in an integrated manner.

The basic components of an FMS can be divided into [45]:

1) Tool machines with counters that can generally identify the pieces arriving from a given center and prepare to carry out the correct manufacturing program.

2) Industrial robots, that is automa s with very high flexibility and governability.

3) Automated transport systems for parts and components which permit high flexibility of movement and reduced lead times.

4) Automatic inventory, generally computer-managed and linked to a database which provides real time information on the state of each inventory cell, thereby providing advantages in terms of manpower reduction, the occupation of available space, and the amount of inventory.

\subsection{Time Compression in Project-Based Firms}

The time compression techniques examined above are beneficial to multi-product processes production firms.

Alongside firms that produce through processes are those that are project-based, either in the form of batches, or personalized lots, or construction, which involve specific and unique products, great works, or specific projects, the development and launch of new production, and the carrying out of advertising campaigns [46].

Precisely because of the unitary nature of every project and the large investment required, three forms of control are called for [47]:

1) Respect of the quality of the project based on customer specifications;

2) Respect of the time schedules, of both the unitary project as well as the phases of progress; time compression must guarantee the project is realized in the minimum time compatible with the technical duration of the various activities, the customer's needs, and the producer's machine-load constraints;

3) Cost control: the costs for carrying out the project must be kept under control; time compression must help to realize the project at the minimum cost compatible with quality and duration objectives.

There are various techniques for the control of time and costs; the most well-known are the CPM (Critical Path Method) [48,49] technique and the PERT times (from Program Evaluation and Review Technique) $[27,28]$, which are particularly appropriate for project-based production process [48]. The methodology of reticular planning and its use in time control can be outlined as in Figure 2.
1) analysis of the project and scheduling of the component activities, specifying for each of these the links with activities upstream and downstream and their duration (in days, weeks or months, in relation to the project's overall scheduling), taking into account available resources and the cost for the assigned duration;

2) construction of the project grid, that is, a logical and graphic model that shows the mapping of the activities, determining the initial and terminal event of the entire project;

3) calculation of the project's duration, or critical path, since if one of its activities starts late and/or its duration is prolonged there is a delay in the completion of the entire project;

4) calculation of the float (slack) of the activities of the other non-critical chains, which for each activity specifies how long the start can be delayed or how much longer its execution can be without compromising the project's completion date;

5) temporal optimization of the project and time compression, by trying to reduce the length of the critical path by increasing that of the non-critical activities and by shifting the freed-up resources to the critical activities; the duration is reduced without cost increases;

6) optimization of costs and thus savings on resources by removing these from non-critical activities when they are not necessary, in order to further reduce the durations of the critical activities;

7) definitive scheduling and explosion of the Gantt diagrams, which places all the activities on a precise temporal scale, ordering them in a logical sequence and specifying for each the effective start date, duration and completion date.

Figure 2. The reticular planning methodology.

\section{Time to Market}

Time to market-conceived as the time needed to conceive, study, plan, begin production, and bring a new product to the final consumer-represents one of the fundamental moments in time compression [9,50]. The high level of global competition today necessitates shortening as much as possible the time to market in order to implement an anticipatory strategy to gain two important competitive advantages [13]:

1) The firm that succeeds in innovating in a timely fashion benefits from greater profitability since, in the initial phases of the new product's life cycle, the firm can set prices that are higher than those its competitors will subsequently set;

2) The rapid development of new products makes it easier to undertake market research through consumer surveys [31].

To reduce the time to market planners and technicians must work together in a more interactive environment that involves everyone in the co-management of the development plan and that produces coordination and cooperation. This relationship should also extend to the suppliers. The integration with suppliers means that quality can be incorporated into the planning from the start, thereby avoiding any wastage of time in fixing design or from errors, in addition to the costs of non-quality [17]. In order to optimize the processes to reduce the 
time to market, various technical approaches have been developed with variants known as High Speed Management, which will be discussed below.

\subsection{High Speed Management}

In 1978, in Japan, a program that incorporated the method to compress the time to market was published; in 1983 Fortune magazine named this High Speed Management (HSM) [29,30,51].

HSM indicates the methodologies for the rapid management of innovation, and it includes several principles that can be summarized as outlined in Figure 3.

High Speed Management contains two approaches:

- Concurrent Engineering,

- Simultaneous Engineering.

\subsubsection{Concurrent Engineering}

The definition of Concurrent Engineering from the Institute of Defence Analysis (IDA) is the following: "Concurrent Engineering is a systematic approach to the integrated, concurrent design of products and their related processes, including manufacturing and support. This approach is intended to cause the developer, from the outset, to consider all the elements of the product life cycle from conception through disposal, including quality, cost, schedule, and user requirements" [52].

Evans [53] and Jo and colleagues [54] introduced several guiding principles for running Concurrent Engineering projects. They are summarized in Figure 4.

\subsubsection{Simultaneous Engineering}

Simultaneous Engineering can be defined as a systematic approach to the integrated, concurrent design of products and their related processes, including manufacture and support. This approach is intended to cause the developers, from the outset, to consider all elements of the product life cycle from conception through disposal, including quality, cost, schedule, and user requirements [52,55].

a) Clarity of objectives in developing new products in order to avoid subsequent changes.

b) Parallelism and simultaneity. The development process includes a number of activities: the total time can be reduced by carrying out these activities in parallel rather than in sequence.

c) Concentration of the projects. Similar projects should be centered on the same planning team, thereby creating the basis for the learning that will lead to time savings.

d) Integration. In order for planning, feasibility and production activities to be properly coordinated there must be strong integration among the organizational functions, thereby creating an information link among the planning and production databases.

e) Technological risk. Projects should be classified according to technological risk in order to avoid continual risk evaluations while they are ongoing.

Figure 3. High Speed Management principles. a) Set customer satisfaction as the final measure of project quality.

b) Integrate all the elements associated with the entire life cycle of the product in the initial phases of development.

c) Start the specific project only after all the elements in the product life cycle have been defined, specified and integrated in the project.

d) Select and involve the suppliers of the most important product parts right from the initial phases.

e) Carry out the project with contributions from all the organizational functions and, if possible, from the final user as well.

f) For each function introduce the possibility to modify previous project choices, by introducing feasible and effective alternatives.

g) Continually improve the development process of new products.

Figure 4. Concurrent Engineering principles.

According to this methodology it is possible to achieve three objectives: the shortening of the time to market, the minimization of the costs of development, and the reduction of the costs of the products by giving up the planning of each individual model while opting for the simultaneous planning of all the models needed to satisfy the variability of market requirements [56].

In particular, for families of products a firm should anticipate the simultaneous ideation and assessment of all the models in the family right from the initial phases of the processes for the renewal of the product portfolio.

The simultaneous planning and designing several models, taking into account the possible variants, will produce a considerable overall reduction in the times and costs of development.

Another important aspect of Simultaneous Engineering is the possibility of minimizing the variety of products, components and processes of production, reducing, on the one hand, the activity times in each phase-and, as a result, the time to market-and on the other the amount of the investments for plants, machinery and equipment for production [57].

After discussing the time compression techniques and the high speed management approach, next section will analyse strategic issues related to time management approaches. Both business and outsourcing decisions are concerned.

\section{Time Is Not Only Speed: Strategic Approach to Time Management}

Time is not only a technical variable to regulate the dynamics of processes but fundamental for the speed of production processes, the length of production cycles, productivity, the reduction in the amortization of fixed costs, and thus the payback period of investments.

Viewed in terms of production and logistical processes, time is a parameter not only of speed but also of punctu- 
ality. With the gradual transformation of production from goods to service goods, punctuality has become a source of competitive advantage [58].

However, the time factor must be assessed from the perspective of the life expectancy of businesses.

Firms develop a portfolio of businesses which form, on the one hand, a system if observed contemporaneously (for example, according to the BCG matrix, businesses are differently economically and financially linked), and on the other a chain if observed in succession [59].

We can thus view a business $B_{n}$ as a link in a chain of business renewals in which its life cycle is not determinable in an absolute way, but only in relation to the business $B_{n-1}$ that precedes it and $B_{n+1}$ that replaces it (Figure 5).

Prolonging the life of $\mathrm{B}_{\mathrm{n}}$ means delaying the start-up of $B_{n+1}$; calculating the optimal replacement time for the replacement of $B_{n}$ would thus mean optimizing the profitability and cash flow of the composite business $\mathrm{B}_{\mathrm{n}}+$ $B_{n+1}$. However, the same reasoning must apply as well for $\mathrm{B}_{\mathrm{n}+2}$, and so on; this means there businesses aren't autonomous in their own profits and financial flows, but rather develop a chain of businesses where the life of each depends on that of the others.

The above discussion leads to an important implication: from the financial viewpoint the time factor can be recognized on the basis of two linked elements: timeliness in starting up a business and, at the same time, timeliness in ceasing operations.

This type of timeliness leads to notable advantages, as being the first to gain a consistent market share [60], setting high prices before the arrival of competitors, to retain loyal customers, fully exploiting the learning of costs in order to gain internal competitive advantages, anticipating the recovery of fixed costs by reducing the risk on invested capital, and obtaining good profitability, which improves the firm's credit capacity for future growth.

Even the anticipation of the business closure is fundamental for competitive success. In fact, closing down $B_{n}$ on time means not only avoiding entering into a phase of non-economic efficiency but allowing the firm to use financial resources that are freed up for $B_{n+1}$, thus short-

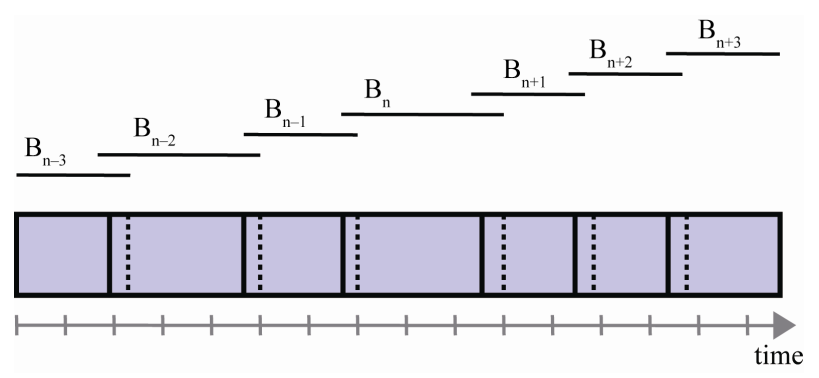

Figure 5. The business chain. ening the business chain. Thus, speed (planning and the launch of new products) and timeliness (substitution of businesses) play a fundamental role in the competitive environment.

Time therefore becomes a critical success factor for leading firms; time management represents an innovative principle in managing the modern firm [15,61], which must develop a time-based strategy [11,62] to perform a time compression in all the transformation, distribution and marketing strategies, which must be based on the principle that time generates value; indeed it is this time value which allows firms to defeat the competition.

\section{1. "Time-Based Competition"}

A "action-reaction" cycle, or competitive control process, must be defined by the set of measures that implement a firm's competitive actions, the resulting market response, and the subsequent reaction by competitors; a reaction that is followed by a new cycle that originates with the counter-reaction of the firm.

A time-based strategy is based on the idea that it is vital to continually speed up the action-reaction cycles so as to increase the competitive tension in the firm's operating environment.

Shortening the action-reaction cycle depends upon the rapidity in processes involving the spread and imitation of innovations. In this regard, benchmarking becomes a fundamental corporate policy that can bring advantages to the follower firm. Thus, it is essential to continually innovate the processes and products not only to anticipate competitors but also to counterbalance their imitative reactions [63]. This inevitably forces firms to shorten their research, design, development and launching times for new products.

The speeding up of the action-reaction cycle is also imposed by the increasingly greater demand for "customized" products and shorter delivery times; production must necessarily focus on increasingly smaller production lots thereby transforming itself in the extreme into production on demand to satisfy the "individual" needs. In addition, production flexibility allows strategies to be based on the variety the product range [6].

Variety-based competitive advantage requires anticipatory competitive behaviour not only in introducing new models but also in renewing the range of winning models.

Finally, a reduction in the action-reaction cycle is made even more necessary in large multi-product, multimarket companies which must reduce the real time required for product and market policies and strategies in order to meet local needs in a timely fashion and adapt their businesses to these needs.

In order to speed up their reaction times, these firms 
must transform the learning capacity of their organizational structures so that they can understand the local situation and improve their market interventions.

The time factor thus becomes even more of a central element in the reorganization of corporate processes that can be termed as time compression and time value.

\subsection{From Time Compression to Time Value}

Assuming that the consumption of time in activities with no, or negative, incremental value generates the inefficient exploitation of a resource and reduces the market response capacity, then time compression must be transformed from a company measure to a policy involving the entire productive chain [64], through intensive use of production and information technologies to speed up the processing of information and the productive transformations.

While the time compression dimension highlights the instrumental value of the time factor as regards efficiency, the time value dimension tends to emphasize the valorization of the use of time within an action-reaction cycle [65].

Time value, in fact, substitutes the "traditional" logic of providing the client with the maximum value at the lowest cost with one of providing the maximum value at the minimum cost "in the shortest time possible", as this produces stable competitive advantages [6].

\section{A Taxonomy of Approaches to Time-Based Strategies}

This study has presented the time compression and time to market approaches as well as the main instruments for formulating time-based strategies. It has been argued that the value of time not only involves a contraction of production and distribution lead times but also deals with the most opportune moment for starting up a business and introducing or withdrawing a new product.

According to Charles Handy, the strategic approach to change can lead to either a strategic drift or a transformational change [66]. The first outcome refers to a gradual change that occurs so subtly that it is not noticed until it is too late, while the second one descends from a radical change.

Assuming a drift or transformational change approach, firms develop different approaches to time-based strategies by implementing different methodologies for time compression. Moreover, firms plan either a divisional or an holistic approach to time compression. By combining the organizational perspective and the strategic approach to time compression, we can identify four different time value approaches (Figure 6).

In the first quadrant of Figure 6, the JIT methodology expresses a strategic drift approach to change assuming an holistic organizational perspective. In fact, JIT programmes develop a continuous improvement [67], providing a strategic drift of incremental changes at each stage of the value chain: operations, logistics, procurement, R \& D and sales departments. In order to be effective, a JIT programme should be spread throughout the organization, thereby changing organizational culture by favouring a learning-based approach to improvement [68].

From this perspective we use the term time saving to refer to the approach firms follow in order to enhance time value through a JIT programme.

The second quadrant (Figure 6) shows strategic changes driven by High Speed Management (HSM) programmes. HSM leads to breakthrough innovations in that it enhances the new product development speed that is fundamental for firms' survival [69].

HSM increases the firm's ability to learn and adapt at the same rate of environmental change, thus favouring transformational change.

It applies to the organizational level in that it embraces all departments in boosting innovative changes and new product development or improvement. According to this perspective, HSM programmes represent a time boosting approach to time value since they reduce the time needed to develop new products, and thus the R \& D costs, as well as increase profits deriving from first-mover strategies.

The "three letter programmes", such as MRP, OPT, FMS and CPM (or PERT), belong to the third quadrant in Figure 6, since they introduce strategic drift changes in a single project or department, such as operations, as well as in procurement. They develop a time rationalizing approach to time value, since they (MRP, OPT, FMS) determine the optimal production lot in order to reduce procurement and inventory costs as well as cut the lead times.

Furthermore, they (CPM, PERT) rationalize the path to achieve efficient project-based processes.

Quadrant four in Figure 6 includes Concurrent and Simultaneous Engineering programmes, the two time compression projects that have a transformational change effect [70]. This fourth perspective follows a time exploiting approach to time value in that, by sharing the knowledge each firm possesses, the value of the time each firm devotes to $\mathrm{R} \& \mathrm{D}$ activities increases following a non-linear trend [70].

The logical path a firm should follow in adopting a time value strategy starts from a project-based strategic drift involving a three-letter programme, in order to test the time compression strategy in a single (or pair) of activities. Subsequently the path should extend to the holistic time saving approach (step 1; Figure 7) and then to the time-exploiting one (step 2; Figure 7). Finally, a HSM programme should be implemented (step 3; Figure 7). 


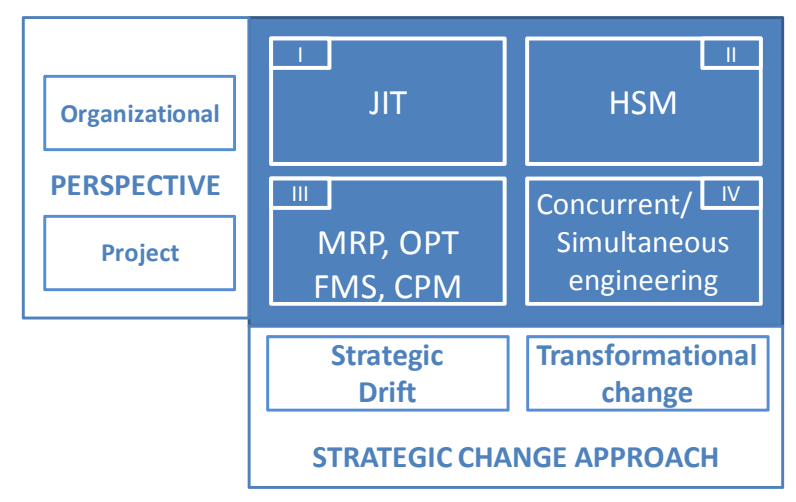

Figure 6. The taxonomy of approaches to time-based strategies.

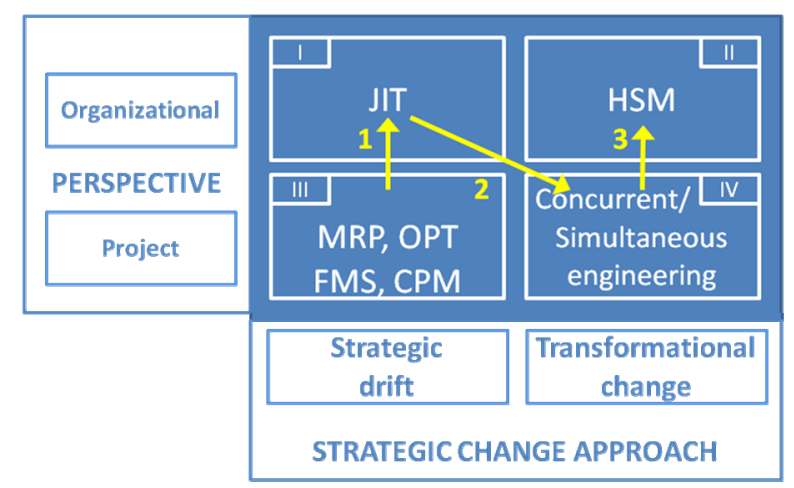

Figure 7. The strategic path to time value.

\section{Discussion and Concluding Remarks}

Time compression is becoming a critical strategic factor affecting the entire organization. Organizations have to compete against time in order to win the competition through both disruptive and incremental innovations. Time-based strategies require a cultural change which drives all the organizational activities towards improvements in time performance, which should be focussed on the parameter of punctuality rather than speed.

Furthermore, time to market represents one of the fundamental moments in time compression. It is strengthened by the adoption of techniques, such as concurrent and simultaneous engineering, which belong to High Speed Management approach.

By analysing the time compression methodologies, we derived a taxonomy of time-based strategies according to two dimensions. While the first dimension relates to the perspective-organizational rather than project-orientedaffected by the adopted time-based strategy; the second dimension involves the approach to strategic changestrategic drift rather than transformational change. The combination of the two dimensions resulted in four different strategic approaches to time compression and time value. A logical incremental path of time-based strategies has been put forward.

Nonetheless, some drawbacks concerning time-based strategies should also be mentioned. We must ask if the time a firm dedicates to improving its response times necessarily entails the sacrifice of some other strategic variable: quality, variety, cost, productive efficiency, or flexibility [31]; and whether time compression does not shift attention away from quality to timeliness.

Moreover, we argue that a strategy based on time also requires the firm to rethink its system of performance measures.

Firms that do not adopt a time-based strategy rely mainly on a system of performance measures focussed on costs and financial results and based on the evaluation of the utilization levels of productive factors by means of a system of productivity measures.

In time-based companies, on the other hand, the focus on costs is replaced by one on time, since cost is considered an indicator of the use of time [31].

In order to measure an organization's performance, measures are used that focus on time for all those activities that can impact the implementation of the strategy, since it is held that performance based on time is much clearer and more direct, and thus more useful, than performance based on cost.

In developing new products firms can adopt time- tomarket measures, broken up into the lead times of the various phases: definition of the product idea, planning, the engineering of product and process, the annual rate of new product introductions, or the number of times the company anticipates its competitors by getting its new products to market first [71].

In line with this approach, the performance system must be a vehicle for organizational improvement and learning as well as for cultural change, thereby leading the organization to shift its focus to the time factor as well as appropriately redefine its control criteria.

\section{REFERENCES}

[1] H. I. Ansoff, "Corporate Strategy: An Analytic Approach to Business Policy for Growth and Expansion," McGraw-Hill, Boston, 1965.

[2] D. E. Hussey, "How to Manage Organisational Change," Kogan Page Ltd., London, 1995.

[3] M. E. Porter, “On Competition, Updated and Expanded Edition,” Harvard Business School Press, Boston, 2008.

[4] N. Rich and P. Hines, "Supply-Chain Management and Time-Based Competition: The Role of the Supplier Association,” International Journal of Physical Distribution \& Logistics Management, Vol. 27, No. 3-4, 1997, pp. 210-225. doi:10.1108/09600039710170584

[5] J. Abegglen and G. Stalk, "Kaisha, the Japanese corpora- 
tion,” Basic Books, New York, 1985.

[6] G. Jr. Stalk, "Time: The Next Source of Competitive Advantage,” Harvard Business Review, Vol. 66, JulyAugust 1988, pp. 41-51.

[7] R. Towill, "Time Compression and Supply Chain Management-A Guided Tour," Logistics Information Management, Vol. 9, No. 6, 1996, pp. 41-53. doi:10.1108/09576059610148694

[8] R. Mason-Jones and D. R. Towill, "Total Cycle Time Compression and the Agile Supply Chain," International Journal of Production Economics, Vol. 62, No. 1, 1999, pp. 61-73. doi:10.1016/S0925-5273(98)00221-7

[9] K. B. Clark and T. Fujimoto, "Product Development Performance: Strategy, Organization, and Management in the World Auto Industry,” Harvard Business School Press, Boston, MA, 1991.

[10] K. M. Eisenhardt and J. A. Martin, "Dynamic Capabilities: What Are They?” Strategic Management Journal, Vol. 21, No. 10-11, 2000, pp. 1105-1121. doi:10.1002/1097-0266(200010/11)21:10/11<1105::AIDSMJ133>3.0.CO;2-E

[11] G. Stalk and T. M. Hout, "Competing Against Time," Free Press, New York, 1990.

[12] A. P. de Geus, "Planning as Learning," Harvard Business Review, March-April 1988, pp. 70-74.

[13] A. De Toni and A. Meneghetti, "Traditional and Innovative Paths towards Time-Based Competition,” International Journal of Production Economics, Vol. 66, No. 3, 2000, pp. 255-268. doi:10.1016/S0925-5273(99)00140-1

[14] C. P. McLaughlin and J. A. Fitzsimmons, "Strategies for Globalizing Service Operations,” International Journal of Service Industry Management, Vol. 7, No. 4, 1996, pp. 43-57. doi:10.1108/09564239610129940

[15] D. Hall and J. Jackson, "Speeding up. New Product Development. JIT Can Help Put Products in Customer Hand Faster," Management Accounting, Vol. 74, No. 4, 1992, pp. 32-36.

[16] M. M. Helms and L. P. Ettkin, "Time-Based Competitiveness: A Strategic Perspective," Competitiveness Review, Vol. 10, No. 2, 2000, pp. 1-14.

[17] G. Taguchi and D. Clausing, "Robust Quality,” Harvard Business Review, Vol. 68, No. 1, 1990, pp. 65-75.

[18] A. K. Bhattacharya, J. Jay and A. D. Walton, "Product Market, Turbulence and Time Compression: Three Dimensions of an Integrated Approach to Manufacturing System Design,” International Journal of Operations \& Production Management, Vol. 16, No. 9, 1996, pp. 34-47. doi:10.1108/01443579610125570

[19] P. Kotler and J. Stonich, "Turbo Marketing through Time Compression,” The Journal of Business Strategy, Vol. 43, No. 10, 1991, pp. 24-29. doi:10.1108/eb039439

[20] T. Ohno, "The Toyota Production System; beyond Large-Scale Production,” Productivity Press, Portland, 1988.

[21] J. K. Liker and J. M. Morgan, “The Toyota Way in Services: The Case of Lean Product Development,” Academy of Management Perspectives, Vol. 20, No. 2, 2006, pp.

\section{5-20. doi:10.5465/AMP.2006.20591002}

[22] C. A. Ptak, "MRP, MRPII, OPT, JIT, and CIM. Succession, Evolution, or Necessary Combination,” Production and Inventory Management Journal, 2nd Quarter, 1991, pp. 7-11.

[23] W. C. Benton and H. Shin, "Manufacturing Planning and Control: The Evolution of MRP and JIT Integration," European Journal of Operational Research, Vol. 110, No. 3, 1998, pp. 411-440. doi:10.1016/S0377-2217(98)00080-0

[24] W. Jiang and J. Han, "The Methods of Improving the Manufacturing Resource Planning (MRP II) in ERP,” International Conference on Computer Engineering and Technology, Vol. 1, 2009, pp. 383-389. doi:10.1109/ICCET.2009.18

[25] A. Neely, "Measuring Performance: The Operations Management Perspectives,” In: A. Nelley Ed., Business Performance Measurement. Unifying Theory and Integrating Practice, 2nd Edition, Cambridge University Press, Cambridge, 2007, pp. 64-81.

[26] R. W. Schmenner, "Production/Operations Management: From the Inside Out," 5th Edition, Prentice-Hall, Englewood Cliffs, 1993.

[27] R. I. Levin and C. A. Kirkpatrick, "Planning and Control with PERT,” McGraw-Hill, New York, 1966.

[28] M. L. Pinedo, "Planning and Scheduling in Manufacturing and Services,” 2nd Edition, Springer, New York, 2009. doi:10.1007/978-1-4419-0910-7

[29] G. Tuttle, "High-Speed Management and New Product Development,” In: S. S. King and D. P. Cushman, Eds., High-Speed Management and Organizational Communication in the 1990s, State University of New York Press, Albany, 1994, pp. 195-218.

[30] J. Chen and N. Zhang, "Customer Incentives in TimeBased Environment," Service Enterprise Integration Integrated Series in Information Systems, Vol. 16, 2007, pp. 103-129

[31] J. D. Blackburn, “Time-Based Competition: The Next Battleground in American Manufacturing,” Business One Irwin, Homewood, 1991.

[32] S. Hum and H. Sim, “Time-Based Competition: Literature Review and Implications for Modeling," International Journal of Operations and Production Management, Vol. 16, No. 1, 1996, pp. 75-90. doi:10.1108/01443579610106373

[33] M. Hiraiwa and K. Nakade, "Periodicity of Cycle Time in a U-Shaped Production Line with Heterogeneous Workers under Carousel Allocation,” Journal of Service Science \& Management, Vol. 2, 2009, pp. 265-269

[34] C. D. J. Waters, "Global Logistics: New Directions in Supply Chain Management,” Kogan Page, London, 2007.

[35] G. Plenert, "Focusing Material Requirements Planning (MRP) towards Performance,” European Journal of Operational Research, Vol. 119, No. 1, 1999, pp. 91-99. doi:10.1016/S0377-2217(98)00339-7

[36] T. G. Schmitt, "Resolving Uncertainty in Manufacturing Systems,” Journal of Operations Management, Vol. 4, 
No. 4, 1984, pp. 331-345. doi:10.1016/0272-6963(84)90020-2

[37] E. L. Appleton, "How to Survive ERP," Datamation, Vol. 43, No. 3, 1997, pp. 50-53.

[38] O. W. Wight, "Manufacturing Resource Planning: MRP II: Unlocking America's Productivity Potential,” CBI, Boston, 1995.

[39] F. R. Jacobs, “The OPT Scheduling System: A Review of a New Production Scheduling System," Production and Inventory Management, Vol. 24, No. 3, 1983, pp. 47-51.

[40] E. M. Goldratt and J. Cox, "The Goal: A Process of Ongoing Improvement," North River Press, New York, 1986.

[41] H. Boer and K. Krabbendam, “Organizing for Manufacturing Innovation. The Case of Flexible Manufacturing Systems," International Journal of Operations \& Production Management, Vol. 12, No. 7-8, 1992, pp. 41-56. doi:10.1108/EUM0000000001302

[42] A. Kusiak, "Flexible Manufacturing Systems. Methods and Studies," North-Holland, Amsterdam, 1986.

[43] A. Genus, "Flexible Strategic Management," Chapman \& Hall, London, 1995.

[44] J. D. Goldhar, M. Jelinek and T. W. Schlie, "Flexibility and Competitive Advantage-Manufacturing Becomes a Service Business," International Journal of Technology Management, Vol. 6, No. 3-4, 2009, pp. 243-259

[45] J. A. Buzacott and D. D. Yao, "Flexible Manufacturing Systems: A Review of Analytical Models," Management Science, Vol. 32, No. 7, 1986, pp. 890-905. doi:10.1287/mnsc.32.7.890

[46] L. R. Lamberson and R. R. Hocking, "Optimum Time Compression in Project Scheduling," Management Science, Vol. 16, No. 10, 1970, pp. B597-B606.

[47] R. D. Archibald, "Managing High-Technology Programs and Projects,” John Wiley \& Sons, Hoboken, 2003.

[48] J. E. Jr. Kelley and M. R. Walker, "Critical-Path Planning and Scheduling," Proceedings of the Eastern Joint Computer Conference, Boston, 1-3 December 1959, pp. 160-173.

[49] E. Conde, "A Minmax Regret Approach to the Critical Path Method with Task Interval Times," European Journal of Operational Research, Vol. 197, No. 1, 2009, pp. 235-242. doi:10.1016/j.ejor.2008.06.022

[50] Z. Cemal and Ö. Mehtap, "A Field Research on the Relationship between Strategic Decision-Making Speed and Innovation Performance in the Case of Turkish LargeScale Firms," Management Decision, Vol. 46, No. 5, 2008 pp.709-724. doi:10.1108/00251740810873473

[51] S. S. King and D. P. Cushman, "Communication and High-Speed Management,” State University of New York Press, Albany, 1995.

[52] R. I. Winner, J. P. Penell, H. E. Bertrand and M. G. Slusarczuk, "The Role of Concurrent Engineering in Weapon Systems Acquisition,” IDA Report, 1988.

[53] S. Evans, "Implementation: Common Failure Modes and Success Factor”, in: H.R. Parsaei and W.G. Sullivan, Eds.,
Concurrent Engineering: Contemporary Issues and Modern Design Tools, Chapman \& Hall, London, 1993, pp. 42-60.

[54] H. H. Jo, H. R. Parsaei and W. G. Sullivan, "Principles of Concurrent Engineering," in: H. R. Parsaei and W. G. Sullivan, Eds., Concurrent Engineering: Contemporary Issues and Modern Design Tools, Chapman \& Hall, London, 1993, pp. 3-23.

[55] T. Arai, T. Hara and Y. Shimomura, "Scientific Approach to Services: What is the Design of Services?,” Manufacturing Systems and Technologies for the New Frontier, Part 1, 2008, pp. 25-30. doi:10.1007/978-1-84800-267-8 6

[56] J. A. Robbins, "Simultaneous Engineering for New Product Development: Manufacturing Applications,” John Wiley \& Sons, New York, 2000.

[57] M. Yoshimura, "Product Optimization in Simultaneous Engineering”, In: U. Roy and J. M. Usher, Eds., Simultaneous engineering: methodologies and applications, Gordon and Breach Science Publishers, Amsterdam, 1999, pp. 109-134.

[58] M. Jelinek and C. B. Schoonhoven, "The Innovation Marathon: Lessons from High Technology Firms,” Basil Blackwell, Oxford, 1990.

[59] G. A. D. Preinreich, "Annual Survey of Economic Theory: The Theory of Depreciation,” Econometrica, Vol. 6, No. 3, 1938, pp. 219-241. doi:10.2307/1907053

[60] P. G. Smith and D. G. Reinartson, "Making Products in Half the Time," Van Nostrand Reinhold, New York, 1991.

[61] C. Musselwhite, "Time-Based Innovation: The New Competitive Advantage," Training and Development Journal, Vol. 40, No. 1, 1990, pp. 53-56.

[62] R. T. Hise, "The Implications of Time-Based Competition on International Logistics Strategies,” Business Horizons, Vol. 38, No. 5, 1995, pp. 39-45. doi:10.1016/0007-6813(95)90034-9

[63] C. B. Shoonoven, K. M. Eisenhardt and K. Lyman, "Speeding Products to Market: Waiting Time to First Product Introduction in New Firms," Administrative Science Quarterly, Vol. 35, No. 1, 1990, pp. 177-207. doi:10.2307/2393555

[64] M. E. Porter, "Competitive Advantage. Creating and Sustaining Superior Performance,” The Free Press, New York, 1985.

[65] G. Debreu, “Theory of Value,” Wiley, New York, 1959.

[66] C. Handy, “The Age of Unreason,” Harvard Business School, Boston, 1989.

[67] W. I. Zangwill and P. B. Kantor, "Toward a Theory of Continuous Improvement and the Learning Curve," Management Science, Vol. 44, No. 7, 1998, pp. 910-920. doi:10.1287/mnsc.44.7.910

[68] B. Sugarman, “A Learning-Based Approach to Organizational Change: Some Results and Guidelines", Organizational Dynamics, Vol. 30, No. 1, 2001, pp. 62-76. doi:10.1016/S0090-2616(01)00041-9

[69] S. L. Brown and K. M. Eisenhardt, "Product Develop- 
ment: Past Research, Present Findings, and Future Directions," The Academy of Management Review, Vol. 20, No. 2, 1995, pp. 343-378

[70] B. Nooteboom, W. V. Haverbeke, G. Duysters, V. Gilsing and A. van den Oord, "Optimal Cognitive Distance and Absorptive Capacity,” Research Policy, Vol. 36, No. 7,
2007, pp. 1016-1034. doi:10.1016/j.respol.2007.04.003

[71] P. L. Carter, S. A. Carter, S. A. Melnyk and R. Handfield, "Identifying the Basic Process Strategies for Time- Based Competition," Production and Inventory Management Journal, Vol. 36, No. 1, 1995, pp. 65-70. 